\title{
SOCIAL MEDIA AND FEAR: SOCIAL MEDIA AS A CATALYST FOR POLITICAL FEAR IN THE UNITED STATES
}

\author{
By \\ Shane R. White \\ B.A., University of Louisville, 2015 \\ A Thesis \\ Submitted to the Faculty of the \\ College of Arts and Sciences of the University of \\ Louisville \\ in Partial Fulfillment of the Requirements for the Degree \\ of \\ Master of Arts in Political Science \\ Department of Political Science \\ University of Louisville \\ Louisville, Kentucky
}

December 2020 
By Shane R. White

All rights reserved 

SOCIAL MEDIA AND FEAR: SOCIAL MEDIA AS A CATALYST FOR POLITICAL FEAR IN THE UNITED STATES

\author{
By \\ Shane R. White \\ B.A., University of Louisville, 2015 \\ A Thesis Approved on
}

November 19, 2020

By the following Thesis Committee:

\begin{tabular}{c}
\hline Dr. Jason Gainous \\
\hline Dr. Adam Enders \\
\hline Dr. Margaret D'Silva
\end{tabular}




\section{ACKNOWLEDGMENTS}

I would like to thank my family for their patience and understanding during the time I committed to this project. I would like to thank Dr. Gainous for his teaching and mentorship over the last 10 years from Intro to American Government through the end of my Masters Degree. I would like to thank Dr. Enders and Dr. D'Silva for their time and advice serving as part of my Thesis Committee. As well as to others who supported and helped me through this time.

Sincerely to everyone, Thank you. 
ABSTRACT

SOCIAL MEDIA AND FEAR: SOCIAL MEDIA AS A CATALYST FOR POLITICAL FEAR IN THE UNITED STATES

\author{
Shane R. White
}

November 19,2010

Abstract: Using the American National Election Study data from the 2012 and 2016 surveys I explore how social media usage shapes fear. This is likely caused by the nature of social media leading to oversharing of sensationalized articles likely to elicit an emotional and fearful response. My findings suggest first that social media usage has a statistically significant effect on whether they would say they are afraid of a candidate (2012) and how afraid they say they are of the candidates (2016). Second, social media has little effect on economic fear, and may actually make people more hopeful about the economy. Third, that this effect is strongest amongst millennial voters. 


\section{TABLE OF CONTENTS}

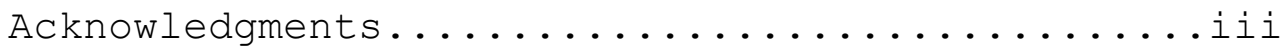

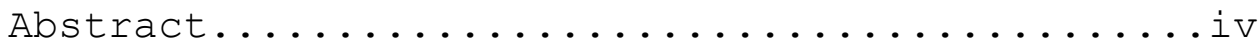

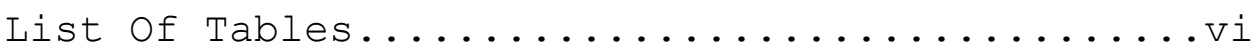

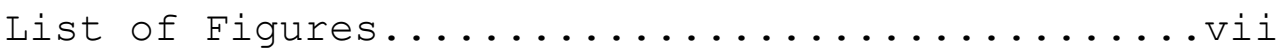

Chapters

I. Introduction.......................

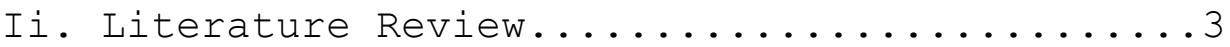

Social Media And Political Behavior.......4

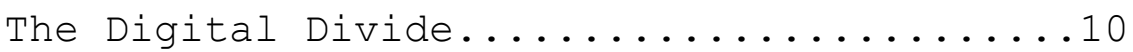

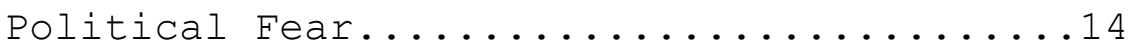

Media's Impact On Emotions.............19

Social Media And Emotions.............20

Social Media Use And Fear.............23

Social Media Use And Political

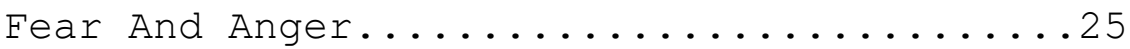

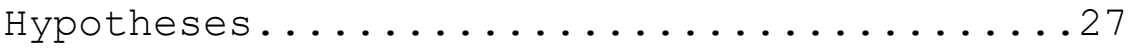

Iii. Data And Measurements...............29

Iv. Analysis And Results................45

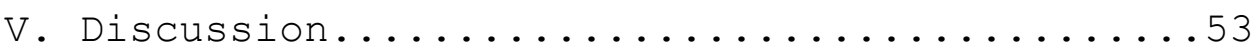

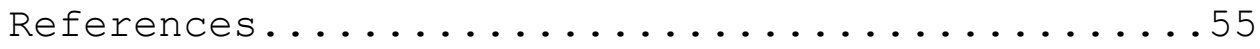

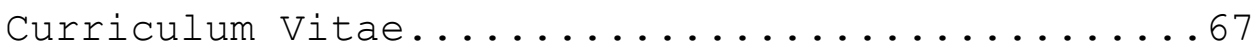




\section{LIST OF TABLES}

4.1. 2012 Candidate Fear Regression.........45

4.2. 2012 Economic Fear Regression..........47

4.3. 2016 Candidate Fear Regression..........49

4.4. 2016 Economic Fear Regression..........51 


\section{LIST OF FIGURES}

3.1. 2012 Social Media Usage Index..........31

3.2. 2016 Social Media Usage Index..........32

3.3. 2012 Candidate Fear Index.............34

3.4. 2016 Candidate Fear Index.............35

3.5. 2012 Economic Fear Index.............37

3.6. 2016 Economic Fear Index..............37

3.7. ANES 2012 Candidate and Economic Indices..43

3.8. ANES 2016 Candidate and Economic Indices..44

4.1. 2012 Social Media Usage and

Fear of Candidates............46

4.2. 2012 Social Media Usage and

Economic Fear.................48

4.3. 2016 Social Media Usage and

Fear of Candidates..............50

4.4. 2016 Social Media Usage and

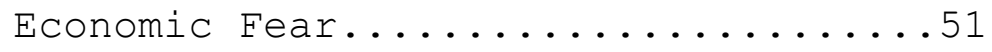




\section{CHAPTER 1: INTRODUCTION}

Social media has become an increasingly large part of our lives. Social media has evolved since Myspace started in 2005, it now adds several platforms including Facebook, Twitter, Instagram, Snapchat, and LinkedIn. These have become core pieces of our identity, pieces that people can anonymously peruse and judge. Many of us spend hours a day reading statuses and tweets, looking at pictures and other posts. Many are using it to aggregate news and information feeds all into one place.

People often feel that the world is becoming a meaner, scarier, more dangerous place. News articles run sensationalized headlines, like the Time magazine headline "Why Americans Are More Afraid Than They Used to Be" (Rothman, 2016) or the Rolling Stone article "Why We're Living in the Age of Fear. This is the safest time in human 
history. So why are we all so afraid?" (Strauss, 2016), while hard data says something different. The world is becoming a safer and less dangerous place. As a culture, we are standing up to the abuses subjected on many of our peers in the past. There is no longer a looming threat of nuclear war, and terrorism, the 21st century equivalent, is exceedingly rare in most of the world. But, fear does seem to be increasing. Social media algorithms show us only things it assumes that interest us. Has this made horrifying click bait seem even more prominent or enticing? Has this made fear about

Using data from the 2012 and 2016 American National Election Studies, I demonstrate that social media use does have a prominent correlation with political fear. This effect seems likely to grow and affect our society more and more as we progress in the digital age. 


\section{CHAPTER 2: LITERATURE REVIEW}

To study how social media use catalyzes political fear,multiple factors must be examined. Direct observation of this causal relationship is impossible; there are no statistics that are evident or brain scan that can be easily done. Therefore, I will develop the relationship between variables we can observe, and why those observations are likely to be links in the causal chain that social media is catalyzing political fear.

I will review how social media's effect on political behavior has already been established. I will also review the digital divide leaves some populations more vulnerable to influence and manipulation. Furthermore, I will address how fear impacts political behavior in general. I will examine how social media affects emotions in general, then more specifically fear. The media, in general, affects political fear, and I propose that social media directly influences political fear. 
Social Media and Political Behavior

Social media and the internet have changed the way people interact with each other and their governments. The ways in which they are able to interact with each other have changed dramatically with the advent of social media. Many of our traditional venues for interaction with each other or our local political leadership are fading away (Putnam, 2000). The internet has developed a new venue for interacting with each other and our politics, be it through engaging in political discussion or through interaction with political actors (Bimber, 1999; DiMaggio et al, 2001).

The precarious conclusion is that the changes in behavior are a result of events that lead from exposure, causing a change in attitudes and opinions, to the resultant actions (Kruglanski et al, 2015). It assumes that while the person is using social media they are exposed to stimuli that trigger a strong emotional reaction, such as fear or anger, making them want to take action in the situation, more than specific behaviors that would be more comfortable for them (Knoll et al, 2020).

Further complicating this question of a causal chain between the stimuli to actions, we are looking at whether the emotional and attitudinal pressure builds up to the 
level of inspiring impactful actions, or whether the release of pressure of a low effort form of political action, such as a tweet, status update or post keeps the internal pressure from building to the point that real behavioral change requires (Hassid, 2012; Kristofferson, $2014)$.

While controversial, because it seems a questionable causal argument, studies suggest that social media use has fanned the flames of many protest actions around the world (Bekmagambetov et al, 2018; Gainous et al, 2015;2017). The more frequently people participated in online debate, the more likely they were to participate in the collective action that connects people around a shared grievance (Alberici \& Milesi 2013) .

While there is some fear that it may cause younger generations to eschew traditional political participation (Gainous et al, 2015), it seems clear that there are influencing factors in play, even the dreaded "slacktivism" isn't entirely lost effort. People who engage even in token activity are more invested in a cause than someone who has not been involved in any way. Because only a fraction of people take part in action, it doesn't manifest the desired change, when millions commit their support to making 
something happen, however they are more likely to be involved after a simple investment than otherwise (Chou et al, 2020; Boulianne \& Theocharis, 2018). There is a strong correlation between online political activities and taking part in offline, and more traditional, political participation from contacting politicians, protesting and simply voting (Boulianne \& Theocharis, 2018)

This seems to be made evident by the number of governments that are attempting to influence political behavior by influencing the "digital commons" that social media usage explores. Gunitsky (2015) addresses how governments use social media to rile up counter movements, to framing a cause in different lights to change the framing of the movement, autocratic, semi-autocratic governments and candidates see the power that social media has on political behavior, and utilize it to increase their influence on the populace (Gunitsky, 2015). The flow of information that people experience through the internet has a significant effect on people's opinions about their own government. These opinions can be manipulated by the government in question or other organizations affecting the flow of information(Gainous et al, 2016). 
People will use a medium that they trust to get their news. In places where traditional media is primarily controlled, or at least influenced, by the government, they have been able to manipulate people into holding higher levels of trust. While people who are using social media are seeing information from trusted individuals that may be critical of the government. Those people who use social media are significantly more likely to have an emotional response that leads to action (Gainous et al, 2018).

Governments are also investing time, expertise, and money into directly influencing the algorithms that control what is visible on social media, and it's more passive effect on the populace, and its tendency to passively stratify issues and perspectives (Katzenbach, 20109). This influence can allow governments to passively censor things by keeping radical ideas near the bottom of the feed, while still allowing those with radical ideas to share and vent. However, it isn't just governments that censor social media. Through the collection of forums that makes up much of modern social media, people are able curate their feeds to decrease the amount of undesirable concept exposures, and ordinary people who are moderating their forums, from Reddit to Facebook groups, have the ability to censor out 
viewpoints they disagree with. This can substantially shift the perceived dialogue and change the political conversation (Ashokkumar et al, 2020).

The effect social media has on campaigns can also be seen as a positive in many ways. Many candidates use social media to broadcast an image of not being part of the "establishment" (Gainous and Wagner, 2014) to separate themselves from career politicians that many people see as the "problem". President Trump in 2016 was often seen as "authentic" by many of his followers, he led a campaign that was seen as amateurish and not the kind of campaign that a professional politician would use to run for president. This is especially evident when compared to the highly professional campaign of Hilary Clinton. But, this perceived difference led to excitement and trust that propelled him into office (Enli, 2017)

The internet has long been feared as a method to incite polarization. Much of our common ground is weakened when we get news from our preferred sources, rather than shared common ground. This leads to increased anger at the opposing party (DiMaggio et al, 2001; Hasell \& Weeks, 2016). Social media has accelerated this polarization on the political spectrum. Grover (2019) suggests that this 
can be linked in part to the difference in messaging of major candidates in an election. Candidates are able to use social media to influence party attitudes, by making personal views into specific political positions, and making that part of the platform. The ensuing shares and retweets allow it to appear as a part of the parties mainstream beliefs (Grover et al, 2019).

Social media also allows people to let out their anger and hate through social media, with little consequence. This lack of self moderation leads to people having more extreme attitudes and increased conflict (Altheide, 2016). 
The Digital Divide

Political participants are not all influenced equally by social media and the internet. There are several major areas of "digital divide" that affect the way people access the internet, what people do when they access the web, the quality of an individual's access, and what types of social media they use.

This divide has multiple distinct rifts. Quality of access is one of the first issues. Access varies from country to country and is impacted by, and directly affects the economics of each country. Poorer populations are less able to afford internet access. Because of the relative poverty, development of infrastructure that lowers cost and adds accessibility is unattractive. Cultural and language variables play a direct role on internet usage; those able to understand languages spoken by larger populations are distinctly advantaged over those who speak smaller and local dialects (Guillen \& Suarez, 2005). Many of the same issues impact access in rural areas, where access may be slower, and urban areas, where there is limited cost effective, quality internet connection. The cross-cultural divide between rural and urban cultures also has affected 
the amount of time it has taken for those populations to adopt internet use (Hindman, 2000).

In rural areas, this lack of experience with the internet leaves people with less "information literacy." This leaves them more vulnerable to misleading and abusive content on the internet. Whether fake news, or people trying to defraud them, rural populations are more vulnerable to those trying to take advantage of them (Yu et al, 2017;2015).

Many of those factors have decreased through time, trade, and cultural imperialism. People throughout much of the world have access to the global economy through the internet than ever before (Friedman, 2005). The legacy of lack of access in those areas still impacts the populations of those countries and rural areas as a whole. This economic element of the digital divide that has had a lasting impact on the people's health, education, communication, and economic viability. This exacerbates the issue leading to groups falling further and further behind (Bertot, 2003). Those who are digitally disadvantaged are more vulnerable to behavioral control and emotional manipulation through those mediums (Hsiah et al, 2006). 
Another critical rift is age, older populations are generally less likely to use the internet than younger groups. Their use of social media is also a more recent development, generally motivated by social connection to friends and family (Friemel, 2014).

This divide doesn't heavily impact the economic potential of the older populations. Older populations are often either firmly established in their careers, or retired (Hunsaker \& Hargittai, 2018). While it is heavily affected by their socioeconomic status, it is exacerbated by older populations' lack of desire, or perceived need, to adopt new technologies (Niehaves \& Plattfaut, 2014).

This digital divide impacts their health, both social and physical. This use both increases mental activity, lowering the risk of developing mental impairment, and increases education about health issues they are facing (Hunsaker \& Hargittai, 2018).

Social interactions are also dramatically lower amongst seniors that don't use the internet. This has a negative impact on their community connections and social capital (DiMaggio et al, 2001). They are also left more vulnerable to disinformation due to lack of "information literacy" (Yu et al, 2015). 
This concept of a digital divide leads to both digitally advantaged and disadvantaged groups. The disadvantaged groups may be more vulnerable to fake news and populist propaganda, making them more easily influenced. Fear is often utilized in many types of propaganda, and can be very effective at influencing political behavior. 
Political Fear

Political fear has been examined most commonly as a precursor for a political ideology. Evidence suggests that fear is a precursor for conservative ideas and beliefs, or that a specific set of cognitive biases are related to conservatism. That the inability to cope with underlying fear and uncertainty plays a role in the development of conservative political beliefs(Jost, et al 2003).

Perceived threat, regardless of political identification, is shown to impact support for policies of varying kinds. People with identified fear supported action in Afghanistan at a higher rate post 9/11 then others, regardless of political disposition(Huddy, et al 2005).

The physiological fear response is notably different in people. Those who have a stronger startle response to gunshots or threatening images were more likely to have strong feelings about security. The manifestation occurs in various ways, such as being pro gun and owning weapons, or being in favor of increased defense spendingloxley et al $2008)$.

Critically, fear is shown to directly affect political behavior. Fear is shown to have a significant effect on 
political participation when competing for resources; fear and anger both had a dramatically stronger effect than enthusiasm. When controlling for political skills and resources, fear also had the strongest effect of the emotional categories. For "cheap" participation such as a bumper sticker, voting or talking about a candidate, fear has a stronger effect on political behavior than enthusiasm or anger, although anger is far more likely to illicit contributions (Valentino et al, 2011).

Fear has played an increasing role in our political discourse. Past politicians stoked fear of outside forces, such as Nazis or Soviets; now leadership plays on fear of internal opposition. A cultural divide has developed that creates a primal "us vs them" response, causing people to fear the position of the other team, and that it will harm them(Iyengar et al 2014).

Populist candidates throughout the world are found to use political messaging and appeals that are more likely to use negative emotions. Fear, anger, disgust and sadness are used far more often to elicit strong responses (Windmann, 2020). As a wise alien once said "Fear is the path to the dark side...fear leads to anger...anger leads to hate...hate leads to suffering" (Lucas, 1999) While not an authority on 
psychology, there is truth to the idea that negative emotions can lead to a powerful and dangerous wave of political power that populist candidates have ridden to power in many places and times.

Fear encourages people to speak their minds, it triggers the fight or flight response which either way, leads to action. Altheide (2016) suggests that Trump purposefully incited political fear, and pushed people to "speak their minds." This allowed people to bring their bigotry and impulsivity to the forefront. Social media then allows people a nearly consequence free place to spit their vitriol. This magnified the emotional momentum and led people who would not normally act (vote) to go and act (Altheide, 2016)

Fear is also used by populist candidates by effectively engineering a threat, and then to create a clear and concise answer that their ideological opposites have trouble competing with. If Trump's campaign could make undecided voters afraid of the threat of "undocumented murderous rapist immigrants flowing like a river across the unprotected border" then they tell you that they have a solution, then the opposition's response of, "they aren't a threat, and the solution won't work" is not effective 
because it doesn't deal with the emotional response.

Similar rhetoric was used in Brexit, suddenly politicians were convincing the people that "the rest of the European Union will drag us down and destroy who we are, and so we have a plan to deal with it!" It is much more enticing than the counterpoint, "No they won't". These fear messages not only radicalize their base, they attract voters to take a side on an issue to which they were previously unconcerned (Scheller, 2019). 
Media's Impact on Emotions

The media has utilized and been driven by fear since long before the internet and the silicon valley appended "social" prefix. Traditional media and governments have long used fear as a form of social control. While fear may be obvious as a motivator for anti crime bills or military spending bills, this can be expanded into many other areas of influence. When framing issues with fear, broadcasters have been able to make their stories familiar and the importance of the issue more pronounced (Altheide \& Machalowski, 1999).

The Hollywood media has also changed the way we process and appreciate fears. Fear was made into something fun and interesting through the development of suspense thrillers and horror movies. This further increases the effectiveness of the fear framing by making this something that people are conditioned to be intrigued by rather than something that some people would want to avoid (Altheide \& Machalowski, 1999).

These discourses of fear lead things to be framed specifically through the lens of fear. After the Columbine shooting, media outlets used the leverage of fear to go after specific elements that they believed were 
problematic. They framed "outsiders" as potential school shooters, and used the event as leverage to change the discussion about security and the role of police in school. While intended to make students safer, it would often lead to targeting students who were different from the group or didn"t fit in, in the name of "safety". Getting away from the narrative that people wanted to present and allowing fear to take the center stage (Altheide, 2009). Media's presentation of much of the world through a "problem frame" uses fear to drive a narrative meant to influence the masses and create "social control", allowing the media to continue to profit by keeping people afraid (Altheide, $2004)$.

Emotion is heavily used in journalism, while some "purists" view it as sensationalism and the practice of tabloids, but the news has always been closely intertwined with emotions even when people want to deny it. People connect to the story with their interior world of emotions. But denying that events that affect people are emotionally important does not lead to good reporting, or even good dissemination of information (Peters, 2011). 
Social Media and Emotions

Because of the nature of the hybrid media, all of the ways that traditional media influences emotions are still true for social media, broadcasters and organizations dove headfirst into utilizing social media to advance many of their ongoing efforts. Pulling the new tools into the same mission, just like radio, television and every other major change has been put to use by the actors already in motion (Chadwick, 2017).

Social media, and the fast paced movement of internet users in the social media era, has also accelerated changes in the way the media presents information. Social media prompted a trend towards reducing events into bite size pieces of "news", with a beginning, middle and ending, rather than an ongoing story that affects society. It also accelerated and reduced political communication into simple messages, rather than an ongoing conversation (Altheide, $2004)$.

Catchy and sensationalized titles, often referred to as clickbait, are designed to elicit a quick emotional response to engage readers with the content. Readers become more sensitive to the emotional pleas of this practice, 
rewarding media elements that use this emotional manipulation (Blom \& Hansen, 2014.)

The effects of social media have had both positive and negative effects on journalism and the media. While it fosters connections with journalists, politicians, actors and other public icons, it creates a two way connection that previously did not exist. New players now have the bandwidth to influence media operators as powerfully as traditional politicians and media. Conversely, it also leads to increased harassment and pressures on those people, impacting the emotions and actions of the influencers on our society (Lewis \& Molyneux, 2018).

Social media has a unique set of effects on how people interact with each other and the world, and has new and powerful effects on emotions. Emotions spread like wildfire on social media. Emotionally charged tweets, both positive and negative, are more likely to be retweeted than emotionally neutral and informational tweets. Stieglitz and Dang-Xuan (2014) demonstrate that emotionally charged tweets are retweeted more often, and with less delay between posting, reading and retweets. This increases the likelihood of people using emotionally charged tweets, and inundates the Twitter user with emotionally charged 
material. Emotionally charged information has become dramatically more available to people than strictly objective and data driven information (Stieglitz \& Dang-Xuan, 2013). Further, "soft" news and information about things like relationships and education is much more likely to be engaged with than "hard" news issues like politics or current events (Kalsnes \& Larsson, 2018).

Emotions also directly affect behavior on social media. Anger and fear specifically influence our online behavior in combative ways, different from excitedly sharing. It has been found that angry people are more likely to be involved in online debate, and conflict with other people. This effect is observed with both political and nonpolitical discussions. While it can't be ruled out that it may be the debating online itself that is making them angry, it creates a feedback loop of negative emotion reenforcing the behavior (Wollebaek et al 2019).

Emotional contagion is also a major factor in social media, as the general attitudes of the posts that people see affect both their current emotional state, as well as the ongoing emotional attitude about an issue. Anger also leads to increased sharing or retweeting and posts about a given issue (Kramer et al, 2014). 
Social Media Use and Fear

Social media's effect on some types of emotions have been studied extensively. Specifically there is a large body of literature, both academically and in popular blogs and websites, that addresses the effect Social media has on the "Fear of Missing Out" popularized as the acronym FoMO. This fear is an anxiety that there are rewarding experiences out there that they are missing. This keeps them wanting to be constantly engaged with their social media platforms in order to make sure they don't miss things. This leads to increased distraction and negative academic performance, and increased likelihood of checking texts and notifications while driving decreasing safety for themselves and those around them (Przybylski et al, 2013).

This general stressor can also lead to increased relationship tension as the demands of keeping up with expectations, jealousy of others experiences, and tension that comes from conflict and drama that is specific to the social media experience. These forces create anxiety and strain on people's minds. A negative feedback loop forms in which the anxiety it creates is directly responsible for making users more likely to continue checking their social media to keep up with said conflicts (Fox \& Moreland 2014). 
These social media addictions can also catalyze mental health disorders, especially anxiety. Anxiety is often used interchangeably with fear. One of the obvious primary symptoms of anxiety disorders is varying levels of chronic fear/anxiety throughout life which has been triggered or exacerbated by social media use (Rosen 2013; Woods \& Scott 2016) . 
Social Media Use and Political Fear and Anger

Politicians on both sides of the political spectrum leverage fear, anger and other negative emotions through their social media accounts addressing the population. They use these negative emotions to highlight issues that are critical to their base, and color their statements about each issue with emotional tones to affect the way people think about those issues. This may lead to increased polarization when our political positions are so highly influenced by emotions rather than "ownership" (Enders, Gainous, and Wagner, 2020)

Social media has also been used effectively to spread disinformation and increase Islamophobia in much of the world. By focusing on a threat, political actors are able increase the strength of their general position. By being able to circumvent the "political correct" phrasing and statements through the use of social media, blogs and highly partisan news sources they are able to disseminate ideas that spread naturally and shift the over ideology of a party (Ekman, 2015).

During the Covid 19 crisis Trump has used social media to lash out at, and spread doubt and fear not about the disease, but rather the scientists and doctors who were 
meant to be tracking and treating the disease. Directly using social media to change the dialogue from one of unity against the pandemic and created doubt and anger at democrats or the "deep state" who he believed were hyping the pandemic to make him look bad (Altheide, 2020).

Fear has not been shown to keep people from viewing and searching out alternate political information. It has, in fact, been found to have some effect on encouraging people to go out and find conflicting information. Anger, however, consistently kept people from pursuing sources of information that would present information through an opposing lens, thereby strengthening the walls of the "echo chamber". Both emotions are consistently found to increase online political participation through social media (Wollebaek et al, 2019). 
Hypotheses

First, social media has a distinct effect on emotions that is likely to be stronger than traditional media. Due to the emotionally engaging nature of social media, this could directly affect the behavior of voters. If interactions through social media are able to get people to protest against the government, it should easily have influence on policy positions.

Second, throughout the literature, there is the concept of the "digital divide." It demonstrates that younger populations are significantly more engaged in social media, but also have increased "information literacy" that helps to insulate them from some elements of political manipulation. Digitally disadvantaged populations are more easily manipulated through digital media (Hsiah et al, 2006; Yu et al, 2017;2015) Anecdotally, evidence suggests that it is the older population that is more easily influenced by fear mongering techniques. This could be especially important for the greater body of knowledge if we can demonstrate this increased impact despite the decreased use due to the digital divide.

My hypothesis is that the dependent variable fear increases with our independent variable of social media 
use. Furthermore, this effect will be stronger amongst cohorts that did not grow up with social media, and lack some "internet information literacy" such as Gen X and Boomers. 


\section{CHAPTER 3: DATA AND MEASUREMENT}

The data for this study came from two major sources, and is made up of individual-level data. This data came from the 2016 American National Election Studies, as well as the 2012 American National Election Studies. The American National Election studies is a time-series collection of national surveys conducted during every presidential election since 1948. The questions are split between those designed to track long-term trends, and those designed to help us understand that moment in politics. The 2012 ANES was completed through both face to face $(\mathrm{n}=2,054)$ and internet $(n=3,860)$ surveys for a total of 5,914 observations. The 2016 ANES was completed through both face to face $(n=1,181)$ and internet $(n=3,090)$ surveys for a total of 4,271 observations. My basic strategy is to estimate the relationship between an index of questions that I created to measure fear and determine if it is 
related to an index I created to measure social media usage.

As highlighted above, my analysis is aimed at answering the following questions: does social media usage have a positive impact on self-reported fear indicators? If there is a positive effect between social media use and fear, is that effect stronger in Gen $\mathrm{X}$ and Boomer cohorts?

The first question is whether social media use has a positive effect on self-reported fear and anxiety indicators. This question is analyzed using multiple indexes and using multivariate regression. 
Social Media Usage Index

The first index of social media use was created using social media indicators weighted and measured to accurately measure social media usage. In the ANES 2012 (Figure 3.1)

Figure 3.1

2012 Social Media Usage Index

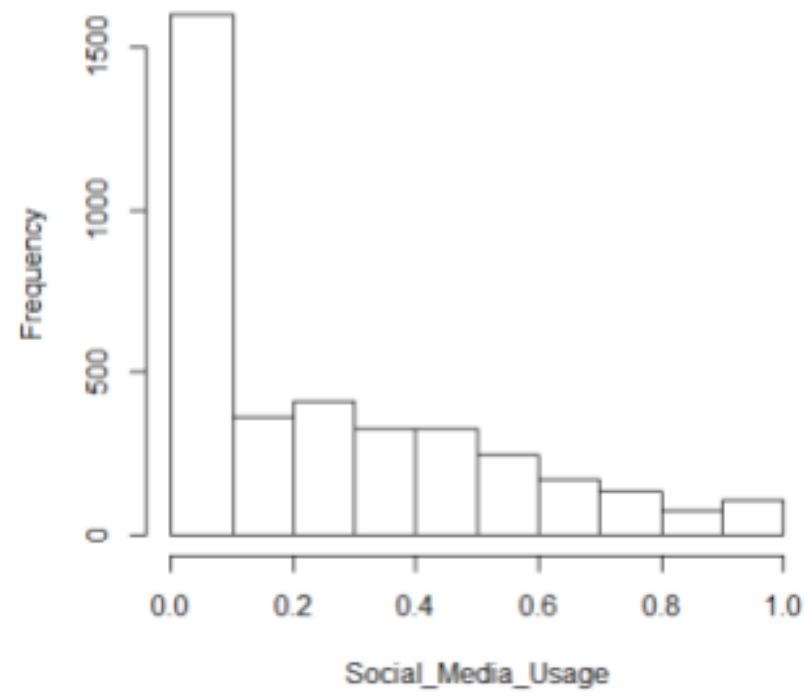

survey data this was

accomplished by using

an additive index of

three items, with a

Cronbach Alpha score of

.71 suggesting a high

internal consistency,

the first is "During a

typical week, how many

days do you use social

media such as Twitter

or Facebook to learn about the election for President?"

The responses were on an eight point scale with answers

that ranged from "None", to "Seven Days". After that

indicator I also used the political affairs profile

variables, "How often politics social media" with answers

ranging from and "Does not apply" to "A lot"; and the

variable "Politics info from social media" with answers

ranging from "Never" to "Every day". The wording of the 
original questions for the political affairs profile variables are not available. All of the variables were ordered so that the higher number is higher levels of social media use, and lower numbers are lower levels of social media use. All three items were rescaled to range from 0 to 1 , while still maintaining the same intervals. This shows distribution heavy in low scores with many people not using social media heavily in 2012 for political purposes

In the ANES 2016 survey data the social media index (Figure 3.2) was created from two items. The first is "During a typical week, how many days do you use social media such as Twitter or Facebook?" The responses were on an eight point scale with answers that ranged from "none", up to "Seven Days". Then the question "How many times did you read, watch, or listen Figure 3.2 2016 Social Media Usage Index

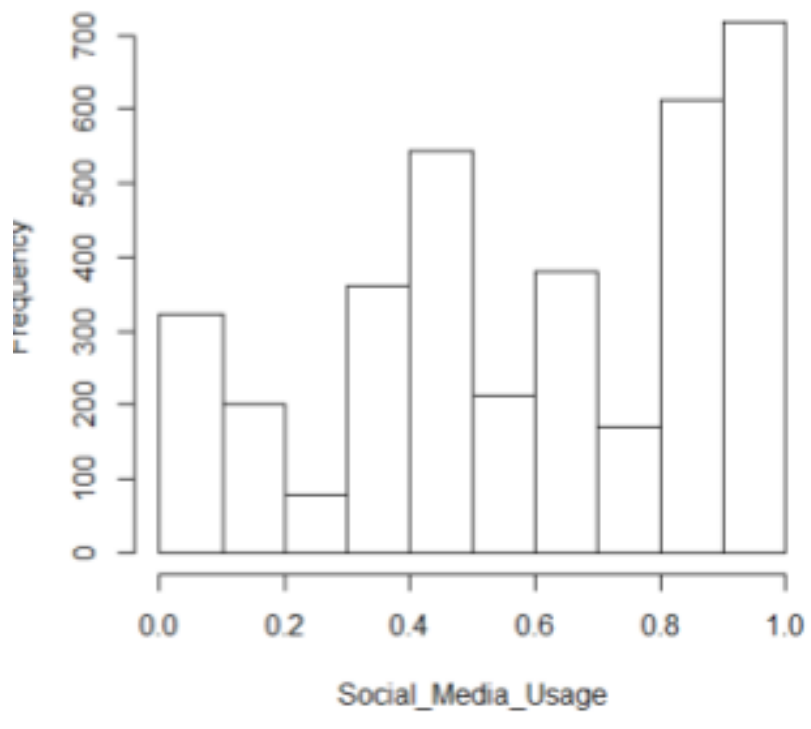
to any information about the campaign for President on the 
Internet?" which had answers on a 4 point scale with answers ranging from "None" to "A good many". Each of these items were ordered so that higher internet/social media use were represented by higher values. Then all items were rescaled to range from 0 to 1 , while still maintaining the same intervals. Then the variables were summed to again create an additive index, with cronbach alpha score of .38, while this does not suggest a high level of consistency, I am using it to create a new variable that measures use of social media for political news. The 2016 distribution is dramatically different from the 2012 distribution because of massively increased social media use, and an increase in its use for political purposes. 
Candidate Fear Index

Then I created my "candidate fear index". This is based on the questions "Does the Republican/Democratic candidate make you feel afraid?" In the 2012 ANES survey data the questions

asked were "Has Barack

Obama, because of the

kind of person he is or because of something he has done, ever made you feel afraid?" Which was answered with a simple "yes" or "no". And "Has Mitt Romney, because of the kind of person he Figure 3.3

\section{Candidate Fear Index}

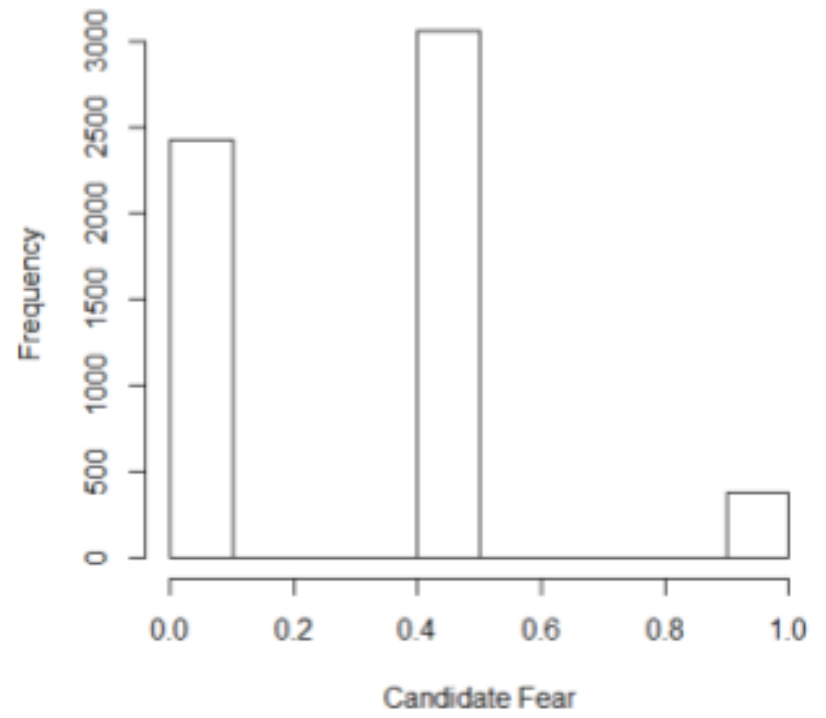

is or because of something he has done, ever made you feel afraid?", which was also answered with a "yes" or "no". The candidate fear index (Figure 3.3) added these two together which created a new variable where most voters said they were afraid of one, many said they were afraid of neither, and a few said they were afraid of both. This item is ordered so that higher fear is represented by higher values, rescaled to range from 0 to 1 , while still 
maintaining the same intervals. The responses to these questions were combined into a single variable, and an average fear was created between the two, this eliminated most of the partisanship bias because it created a measurement of fearing a candidate, rather than a specific candidate.

In the 2016 ANES survey data the questions were "How often would you say you've felt afraid because of the kind of person Hillary Clinton is or because of something she has done?" The counterpart question was "How often would you say you've felt afraid because of the kind of person Donald Trump is or because of something he has done?" Both of these items were measured on the same five point scale

\section{Figure 3.4}

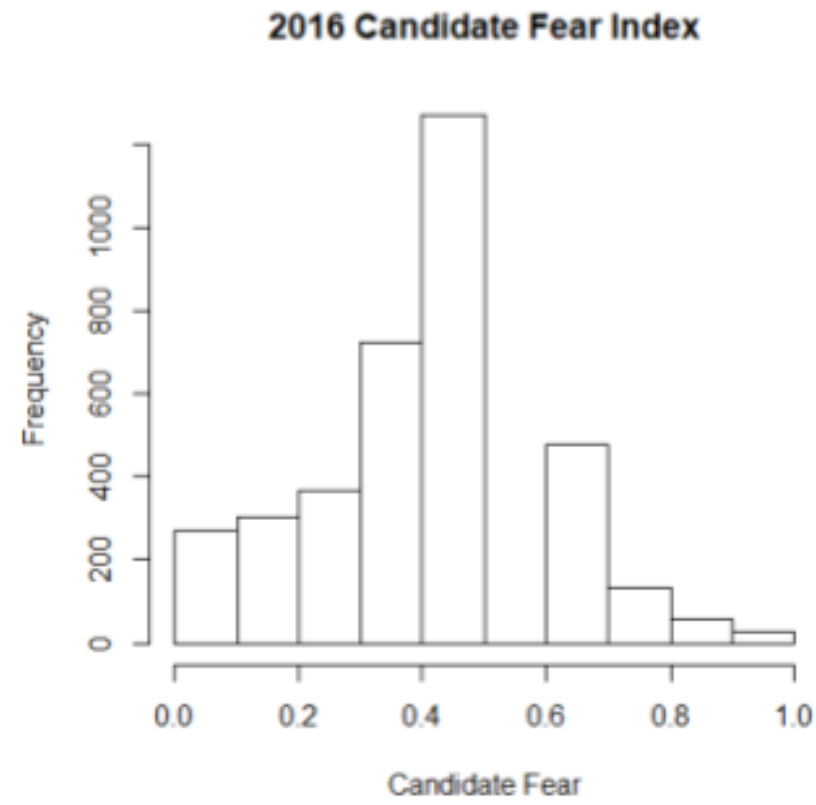

(never, some of the time, about half the time, most of the time, or always). The same procedure was done to add the two variables together to create an average candidate fear index. This index appears very different 


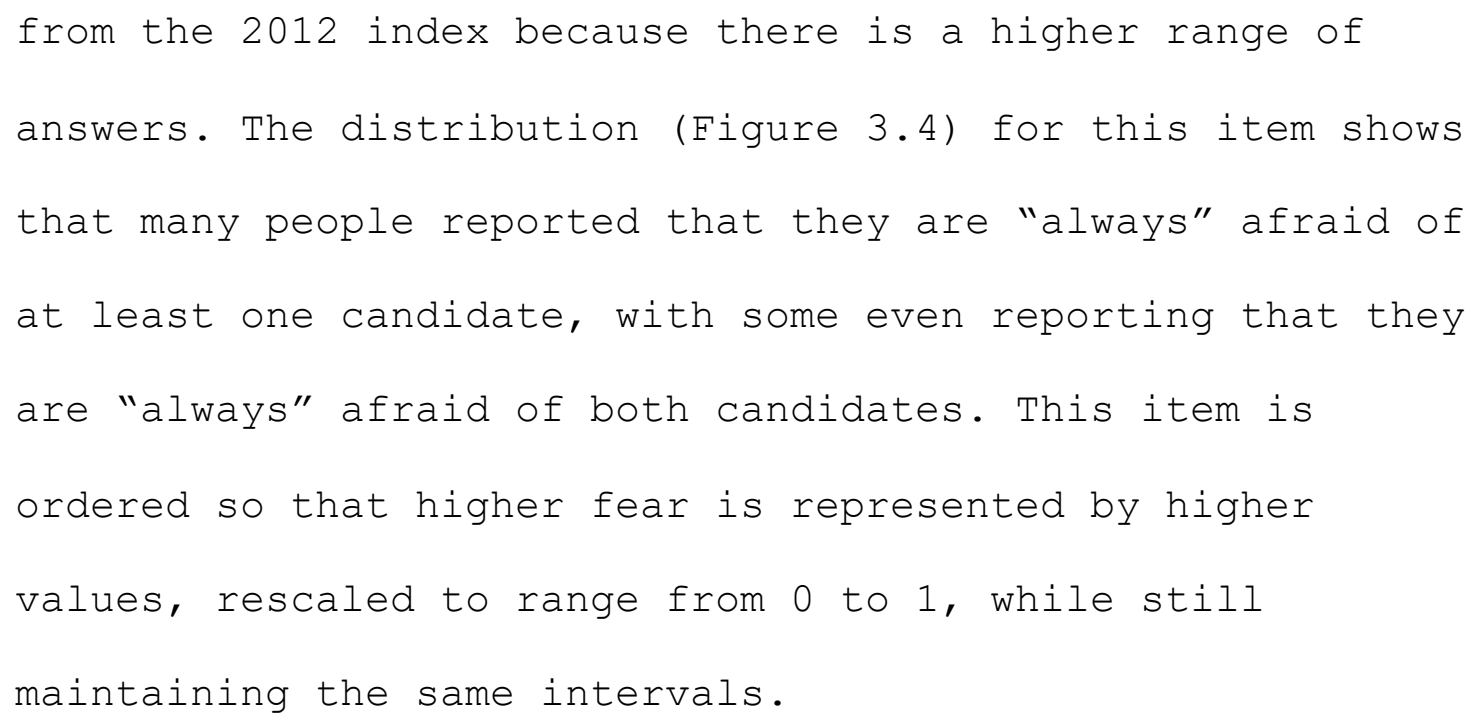


Economic Fear Index

Then a series of questions deemed "economic anxiety" indicators were added together to create my Economic Fear Index. These are questions such as "How much better/worse off will you be next year?", "How much better/worse will unemployment be in the next year?", and "Will the economy be better or worse in the next 12 months?".

In the ANES $2012 \quad$ Figure 3.5

survey data the

questions used in this

index (Figure 3.5) are

"What about the next 12

months? Do you expect

the economy, in the

country as a whole, to

get better, stay about

the same, or get

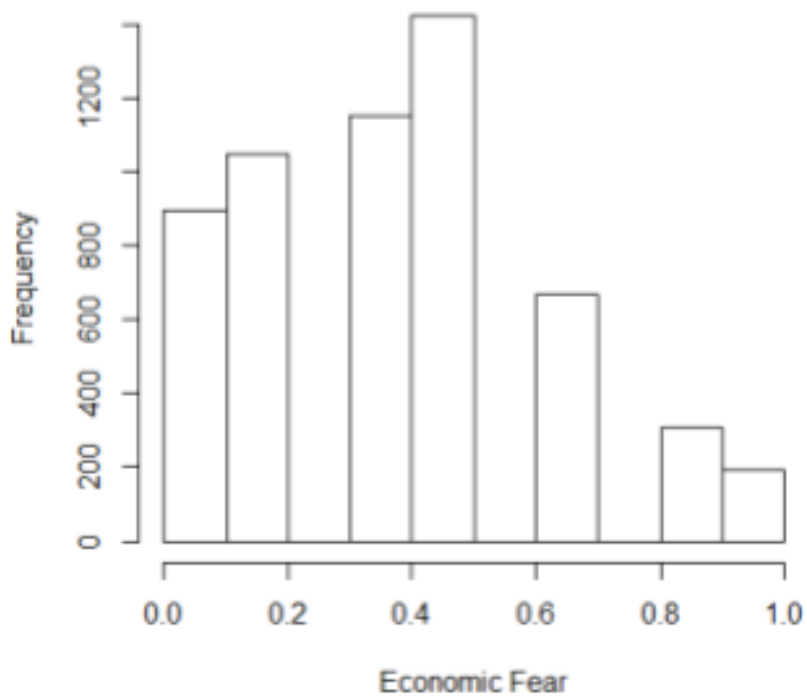

worse?" with the

italicized words being the options on a three point scale.

The next question used was "How about people out of work during the coming 12 months, do you think that there will be more unemployment than now, about the same, or less?" also with a three point scale. Then finally "Now looking 
ahead, do you think that a year from now you and your family will be better off financially, worse off, or just about the same as now?" this item had to be rearranged as worse off was the middle answer. All three of these responses were reordered so that higher economic fear is represented by higher values, then added together using the same procedure as the other indices, and then rescaled to range from 0 to 1 , while still maintaining the same intervals. Then summed into an additive index with a Cronbach Alpha score of .66 suggesting a high internal consistency. The distribution shows that more people believed that the economy would improve than people who believed it would get worse, with the majority clustered toward staying about

\section{Figure 3.6}

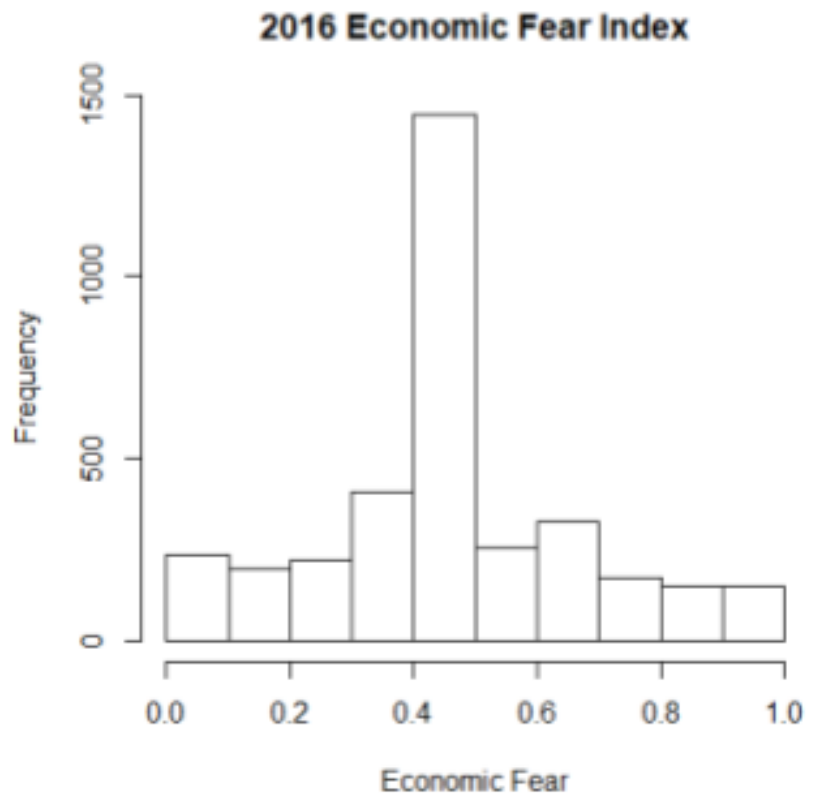

the same.

For the ANES 2016

survey data (Figure

3.6) the first question used was nearly identical as 2012 "What about the next 12 months? Do you expect the economy, in the 
country as a whole, to get better, stay about the same, or get worse?" with the italicized sections being the possible answers on a three point scale. The next question is "How about people out of work during the coming 12 months, do you think that there will be more unemployment than now, about the same, or less?" on a three point scale. The last question in this index is "Now looking ahead, do you think that a year from now you and your family will be much better off financially, somewhat better off, about the same, somewhat worse off, or much worse off than now?" on a five point scale. These were combined into an additive index using the same procedure as the previous index, reordered so that higher economic fear is represented by higher values, and then rescaled to range from 0 to 1 , while still maintaining the same intervals.This index has a Cronbach Alpha score of .56 suggesting a moderate level internal consistency, in the 2016. The distribution for this item shows that the majority believe the economy will stay about the same over the next 12 months, with a roughly even distribution between those who believe it will get better and those that believe that it will get worse. 
Controls

Finally, control indexes such as socioeconomic status, age, ideology, and demographics were controlled for in a multivariate regression model. This included questions in both models for self reported gender, with a two point scale of male and female, with a dummy variable created where females are represented by the higher value. The next control is ethnicity, in the ANES 2016 survey data the respondent was given the options White (non-Hispanic), Black (non-Hispanic), Asian, native Hawaiian or other Pacific Island (non-Hispanic), Native American or Alaska Native (non-Hispanic), Hispanic, and Other (non-Hispanic). On the 2012 ANES survey data the respondent was given the options White (non-Hispanic), Black (non-Hispanic), Hispanic, and Other (non-Hispanic). For both of these questions they were seperated into "White" and "Other" because there were not enough respondents of the smaller minorities to create a representative sample. A dummy variable was created where those who identified as white are represented by the higher value.

Age is represented in such a way that advanced age is represented by a higher value. 
A socio economic status index was also created this included two items that indicated education and income. Both variables were reordered, so that increased income and increased education are represented by higher values. Rescaled from 0 to 1 and summed.

Ideology is controlled by use of the seven point scale liberal/conservative self placement. These were arranged so that those who identified as more conservative are represented by a higher value, and more liberal represented by a lower value. 
Generational Cohorts

The second question centers on whether the correlation between social media use and fear is stronger in Gen $X$ and Boomer cohorts than in the Millennial cohort. I will look at this in a couple of ways. First, during my regression modeling I will determine if the effect gets stronger with age. Then I will subset out each cohort. The cohorts will be drawn from the strauss-Howe generational theory, divided as Boomers, who are those born between 1940 and 1964, Gen Xers, who are those born between 1964 and 1984, and Millenials, who are those born between 1984 and 2000. Each of these subsets will be run through the same regression models and the differences will be evaluated. 
Limitations

Some of the issues I encountered are whether my indicators are effectively measuring fear. The primary fear based question is "Does the Democratic/Republican

\section{Figure 3.7}

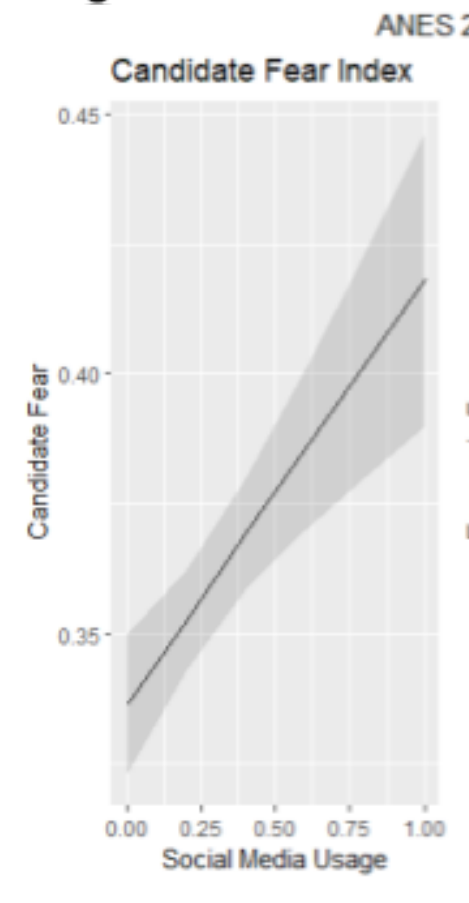

ANES 2012

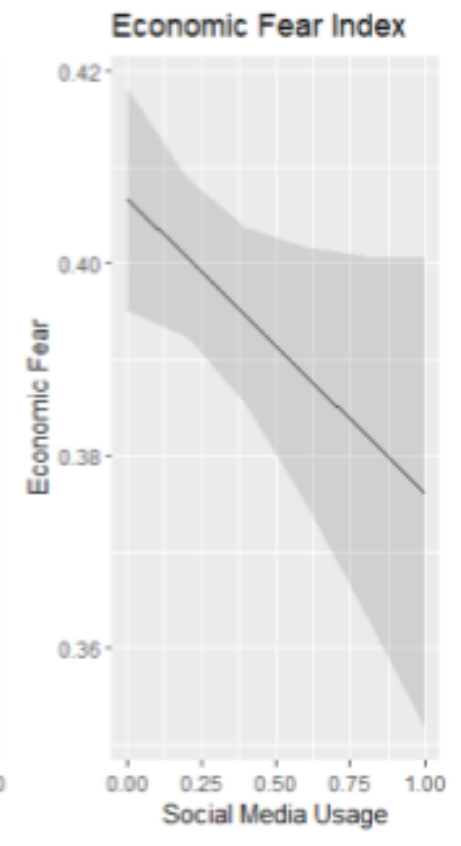

presidential candidate make you feel afraid?" This could be construed as a question that only really measures partisanship rather than fear. The questions about the next year may also not be measuring general fear/anxiety, it might

be that it better measures hope or lack of hope. So the primary issue is whether I can effectively measure fear using the ANES data.

After developing the first model a specific issue though was discerned. Social media Usage had no relevant effect on my initial "Fear Index". I quickly realized the first problem with these hypothesized results: social media use has a different effect on fear of candidates than on 
fear about the economy.

This was the same

Figure 3.8

initial results that

were found in both the

2012 ANES data and the

2016 ANES data.

After discovering

this no more attempts

were made to combine

the Candidate Fear

Index with the Economic
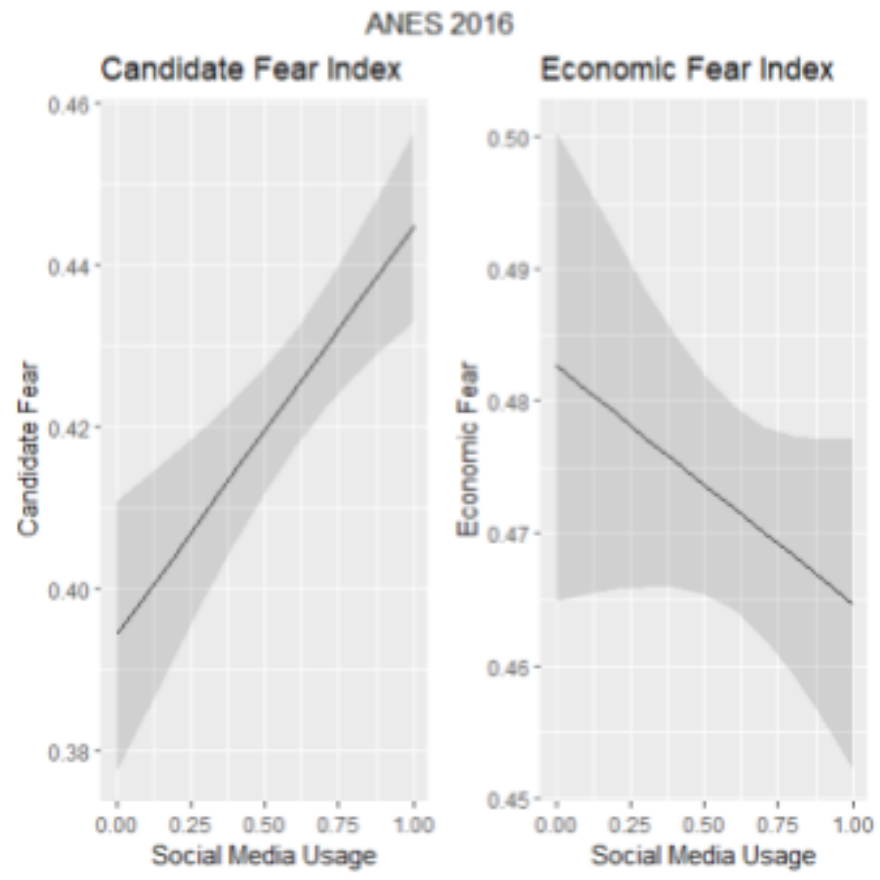

Fear Index and they are treated as separate dependent variables. 


\section{CHAPTER 4: MODELING RESULTS}

Modeling the 2012 ANES Survey Data

The first

model (Table 4.1 \&

Figure 4.1) looks

specifically at

the 2012 ANES

data. Here my aim

was to determine

whether social

media has a

positive effect on

self reported fear
Table 4.1

\begin{tabular}{|lrrrr|r|}
\hline \hline Dependent variable: Candidate Fear & & & \\
& ANES 2012 & Millenials & Gen X & Boomers \\
\hline Social Media Usage & $0.08^{* * *}$ & $0.17^{* * *}$ & $0.08^{* *}$ & $0.07^{* * *}$ \\
& -0.02 & -0.05 & -0.04 & -0.03 \\
\hline Ideology & $0.06^{* * *}$ & 0.08 & 0.06 & $0.06^{* *}$ \\
& -0.02 & -0.06 & -0.04 & -0.03 \\
\hline Age & $0.07^{* * *}$ & 0.05 & 0.14 & $0.14^{* *}$ \\
& -0.02 & -0.23 & -0.1 & -0.06 \\
\hline SES & $0.08^{* * *}$ & 0.09 & $0.12^{* * *}$ & $0.07^{* * *}$ \\
& -0.02 & -0.06 & -0.04 & -0.03 \\
\hline Race & $-0.06^{* * *}$ & -0.03 & $-0.05^{* *}$ & $-0.06^{* * *}$ \\
& -0.01 & -0.03 & -0.02 & -0.01 \\
\hline Gender & 0.001 & 0.01 & -0.005 & -0.01 \\
& -0.01 & -0.03 & -0.02 & -0.01 \\
\hline Constant & $0.24^{* * *}$ & $0.19^{* * *}$ & $0.19^{* * *}$ & $0.20^{* * *}$ \\
& -0.02 & -0.06 & -0.05 & -0.05 \\
\hline $\mathrm{N}=$ & 3,622 & 456 & 1,029 & 1,900 \\
\hline R2 & 0.03 & 0.03 & 0.03 & 0.02 \\
\hline \hline
\end{tabular}

indicators. The results are apparent and statistically

significant. While controlling for major intervening

factors. The results here immediately show that social

media use has a statistically significant effect on

candidate fear indicators. 
This result was

\section{Figure 4.1}
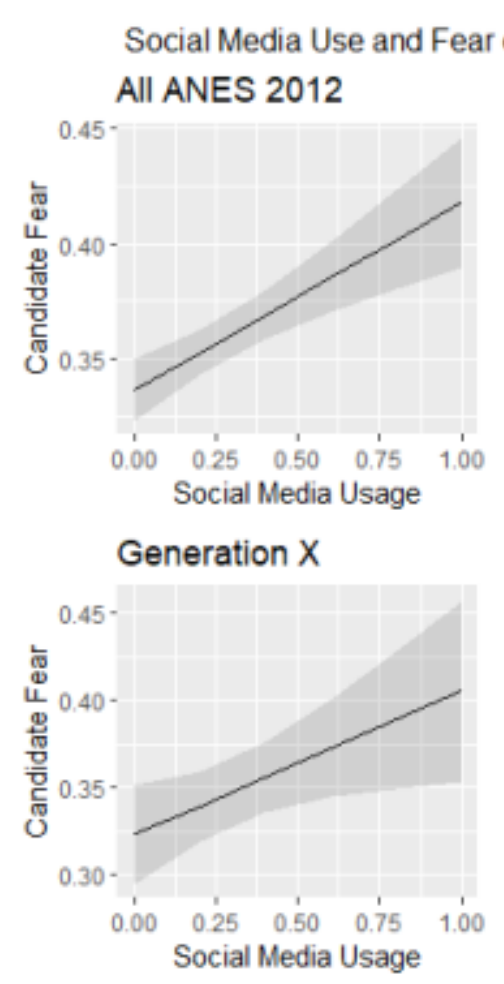

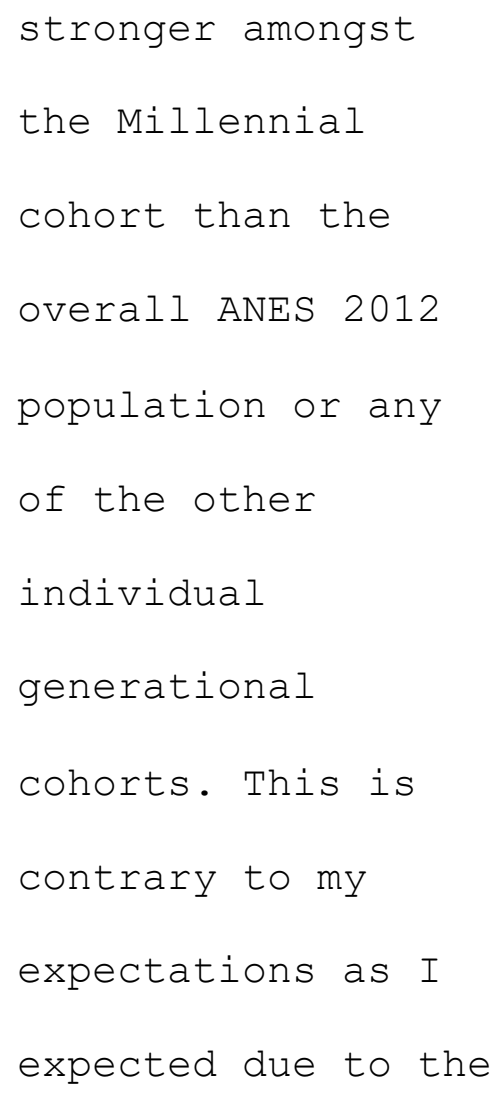

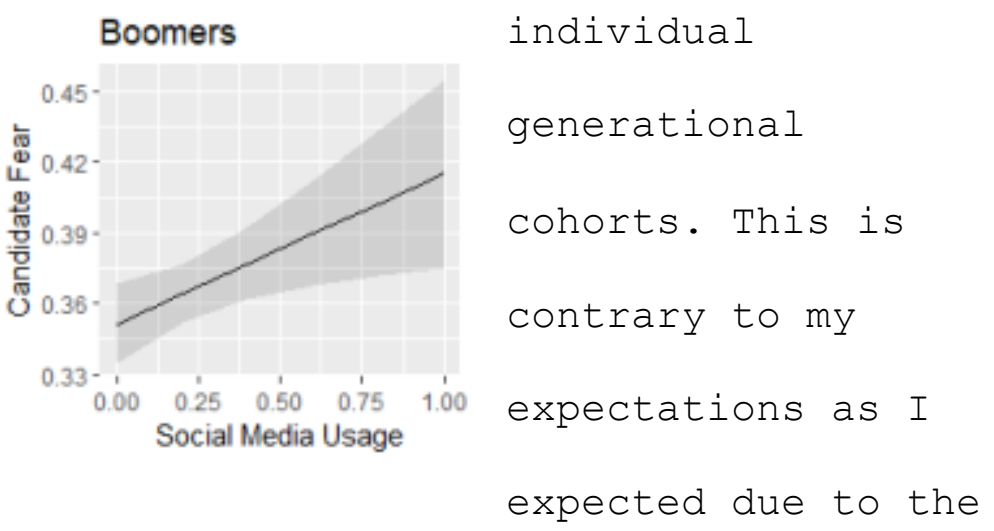

digital divide the older cohorts would be more susceptible to that influence. I was unable to control for the pure volume of exposure that each generation actually receives. Since older populations are less exposed to social media, especially in 2012, having any measurable effect is significant.

I see a significant effect on the dependent variable from ideology where those who identify as more conservative correlated with self reported fear. This is likely because President Barack Obama is a more controversial figure than 
Senator Mitt

Romney whom he

Table 4.2

was running

against. Though

it may also be

related to the

idea that

conservatives may

be more likely to

respond to fear

(Jost, et al

\begin{tabular}{||rrrrr|}
\hline \hline Dependent variable: Economic Fear & & & \\
& ANES 2012 & Millenials & Gen X & Boomers \\
\hline Social Media Usage & -0.03 & -0.01 & -0.03 & -0.02 \\
& -0.02 & -0.04 & -0.03 & -0.02 \\
\hline Ideology & $0.32^{* * *}$ & $0.20^{* * *}$ & $0.30^{* * *}$ & $0.38^{* * *}$ \\
& -0.02 & -0.04 & -0.03 & -0.03 \\
\hline Age & 0.01 & -0.23 & -0.09 & -0.05 \\
& -0.02 & -0.17 & -0.08 & -0.05 \\
\hline SES & $-0.13^{* * *}$ & $-0.13^{* * *}$ & $-0.13^{* * *}$ & $-0.14^{* * *}$ \\
& -0.02 & -0.05 & -0.03 & -0.02 \\
\hline Race & $-0.09^{* * *}$ & -0.03 & $-0.08^{* * *}$ & $-0.11^{* * *}$ \\
& -0.01 & -0.02 & -0.02 & -0.01 \\
\hline Gender & 0.01 & 0.01 & 0.01 & 0 \\
& -0.01 & -0.02 & -0.02 & -0.01 \\
\hline Constant & $0.32^{* * *}$ & $0.35^{* * *}$ & $0.38^{* * *}$ & $0.35^{* * *}$ \\
& -0.02 & -0.04 & -0.05 & -0.05 \\
\hline N= & 3,607 & 457 & 1,028 & 1,886 \\
\hline R2 & 0.14 & 0.08 & 0.11 & 0.17 \\
\hline \hline
\end{tabular}

2003). This

correlation is demonstrated with the positive relationship

between an increase in conservatism and an increase in

candidate fear demonstrated in the ideology result (Table

4.1).

The second model (Table 4.2 \& Figure 4.2) shows that while it has a positive effect, increasing fear about the presidential candidates, it has a weak negative effect on Economic Fear indicators. Respondents across the ANES 2012 data may be slightly less likely to believe that the economy or their individuals financial positions are likely to get worse the more they use social media, although this 
is not a statistically

significant effect.

Figure 4.2

This is

counterintuitive to my

initial supposition

that a person who is

fearful about political

Social Media Use and Economic Fear, ANES 2012

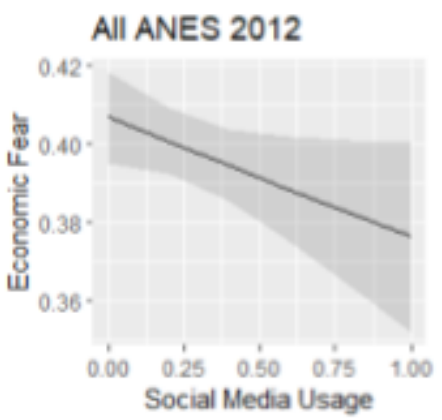

Millenials

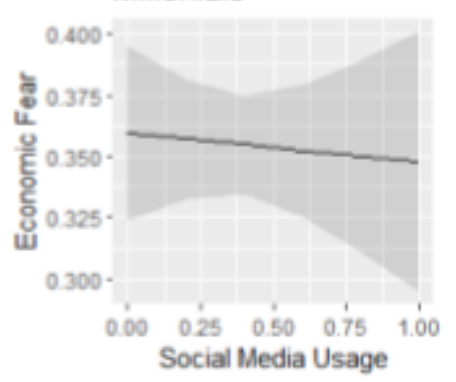

candidates is also

likely to be fearful

about the economy.
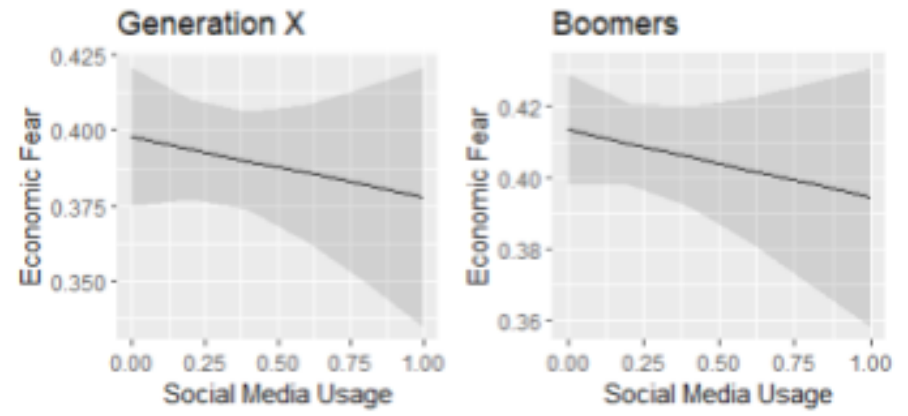
Modeling the 2016 ANES Survey Data

In this second set of models, I look specifically at the 2016 ANES data. Effectively, I am running the same multivariate regressions for the 2016 data as the 2012 data This model has a degree of increased nuance because the questions about candidate fear had a broader gradation than just yes or no. Moreover, there was in general a larger amount of fear in the 2016 elections cycle than there was in 2012. There was also a dramatic increase in social media use across all cohorts from 2012 to 2016. With the majority of people saying they regularly get political news through social media in 2016, rather than a minority saying they ever get political news through social media. This increase in variation of answers allows increased confidence in the 2016 results.

\section{Table 4.3}

In the first

model (Table $4.3 \&$ Figure 4.3) in the 2016 data we see results consistent with our

expectations of seeing a significant

\begin{tabular}{|c|c|c|c|c|}
\hline \multicolumn{5}{|c|}{ Dependent variable: Candidate Fear } \\
\hline & ANES 2016 & Millenials & Gen X & Boomers \\
\hline \multirow[t]{2}{*}{ Social Media Usage } & $0.05^{* \times \hbar}$ & $0.10^{* \star \star \star}$ & $0.08^{2 x k}$ & 0.004 \\
\hline & $=0.01$ & $=0.04$ & -0.02 & -0.02 \\
\hline \multirow[t]{2}{*}{ Ideology } & 0.02 & 0.01 & -0.01 & 0.04 \\
\hline & -0.01 & -0.03 & -0.03 & -0.02 \\
\hline \multirow[t]{2}{*}{ Age } & $0.03^{*}$ & -0.19 & 0.02 & 0.15 \\
\hline & -0.02 & -0.12 & -0.08 & $=0.08$ \\
\hline \multirow[t]{2}{*}{ SES } & 0.02 & $0.08^{*}$ & -0.03 & $0.07^{k n}$ \\
\hline & $=0.02$ & -0.05 & -0.04 & -0.03 \\
\hline \multirow[t]{2}{*}{ Race } & $=0.01$ & $=0.02$ & 0.003 & $=0.02$ \\
\hline & -0.01 & -0.02 & $=0.02$ & $=0.02$ \\
\hline \multirow[t]{2}{*}{ Gender } & $0.03^{*+*}$ & 0.02 & $0.03^{* *}$ & $0.03^{*+1}$ \\
\hline & -0.01 & -0.02 & -0.01 & -0.01 \\
\hline \multirow[t]{2}{*}{ Constant } & $0.34^{* \star \star \star}$ & $0.35^{* \star \star \star}$ & $0.36^{* * *}$ & $0.24^{* x+1}$ \\
\hline & -0.02 & -0.05 & -0.06 & -0.07 \\
\hline $\mathrm{N}=$ & 2,706 & 666 & 866 & 929 \\
\hline $\mathrm{R} 2$ & 0.01 & 0.03 & 0.02 & 0.02 \\
\hline
\end{tabular}


positive effect

Figure 4.3

between social

Social Media Use and Fear of Candidate, ANES 2016

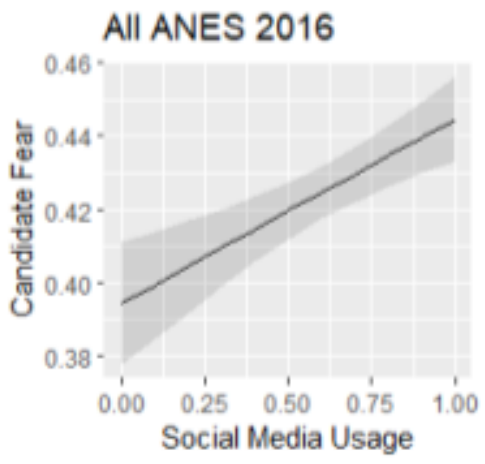

Millenials

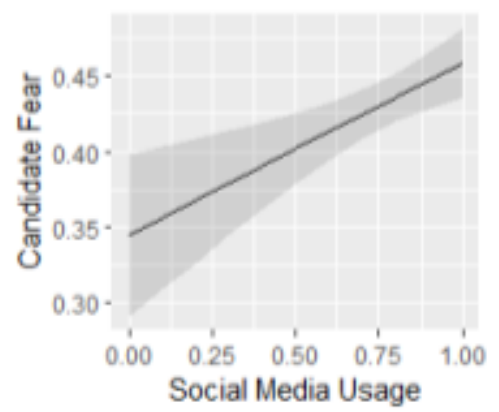

Generation X
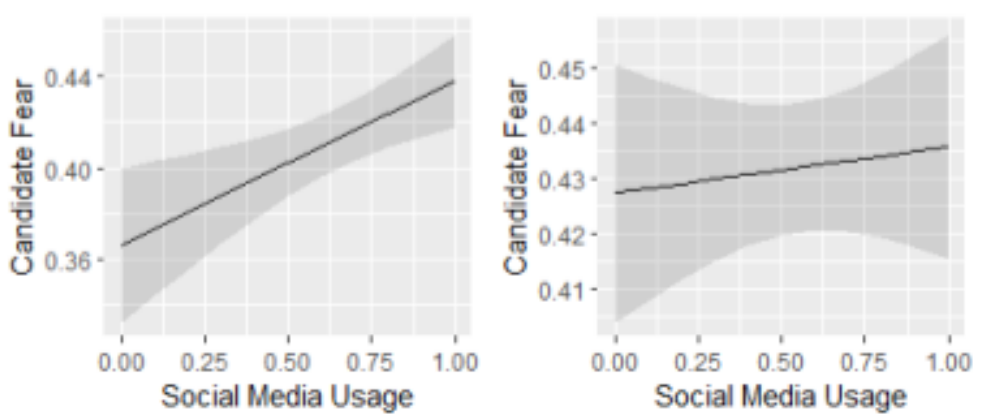

media usage and

candidate fear.

Different from the

2012 models, this

data shows that not only does social

media use have an

effect on the

respondents self

reporting that they

are afraid of the

candidate $(\mathrm{s})$, but it also shows that increased social media usage affects the amount of fear that the respondents are willing to report.

This effect was strongest amongst Millennials and Generation $\mathrm{X}$, and weakest among the Boomer cohort. In this model though we predict an effect amongst the Boomers, it is not statistically significant. This again runs counterintuitive to my initial hypotheses that the effect would be stronger amongst the Generation X and Boomer cohorts. 
Table 4.4

\begin{tabular}{|l|r|r|r|r|}
\hline Dependent variable: Economic Fear & & & \\
& ANES 2016 & Millenials & Gen X & Boomers \\
\hline Social Media Usage & -0.01 & -0.04 & 0.03 & -0.03 \\
& -0.01 & -0.03 & -0.03 & -0.02 \\
\hline Ideology & $0.15^{* * *}$ & $0.05^{*}$ & $0.16^{* * *}$ & $0.17^{* * *}$ \\
& -0.02 & -0.03 & -0.03 & -0.03 \\
\hline Age & 0.02 & -0.14 & 0.14 & 0.09 \\
& -0.02 & -0.11 & -0.09 & -0.09 \\
\hline SES & -0.02 & -0.03 & -0.01 & -0.03 \\
& -0.02 & -0.04 & -0.04 & -0.04 \\
\hline Race & $-0.05^{* * *}$ & $-0.05^{* * *}$ & $-0.05^{* * *}$ & $-0.04^{* *}$ \\
& -0.01 & -0.02 & -0.02 & -0.02 \\
\hline Gender & $0.02^{* * *}$ & 0.02 & 0.02 & $0.04^{* * *}$ \\
& -0.01 & -0.02 & -0.01 & -0.01 \\
\hline Constant & $0.40^{* * *}$ & $0.51^{* * *}$ & $0.30^{* * *}$ & $0.34^{* * *}$ \\
& -0.02 & -0.05 & -0.06 & -0.08 \\
\hline N $=$ & 2,659 & 658 & 848 & 914 \\
\hline R2 & 0.05 & 0.02 & 0.05 & 0.06 \\
\hline \hline
\end{tabular}

2016 economic

model came out

basically the

same, showing that

social media use

still has a

negative effect on

economic fear. The

only significant correlations with

economic fear ideology

with those who

identified as more

conservative having a

higher self reported

economic fear.

The overall

increase in fear about

political candidates

caused by social media

\section{Figure 4.4}

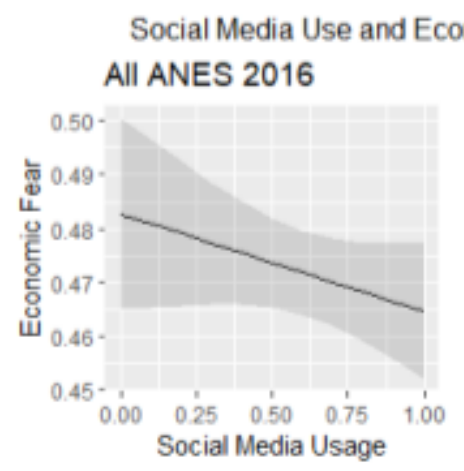

Generation X
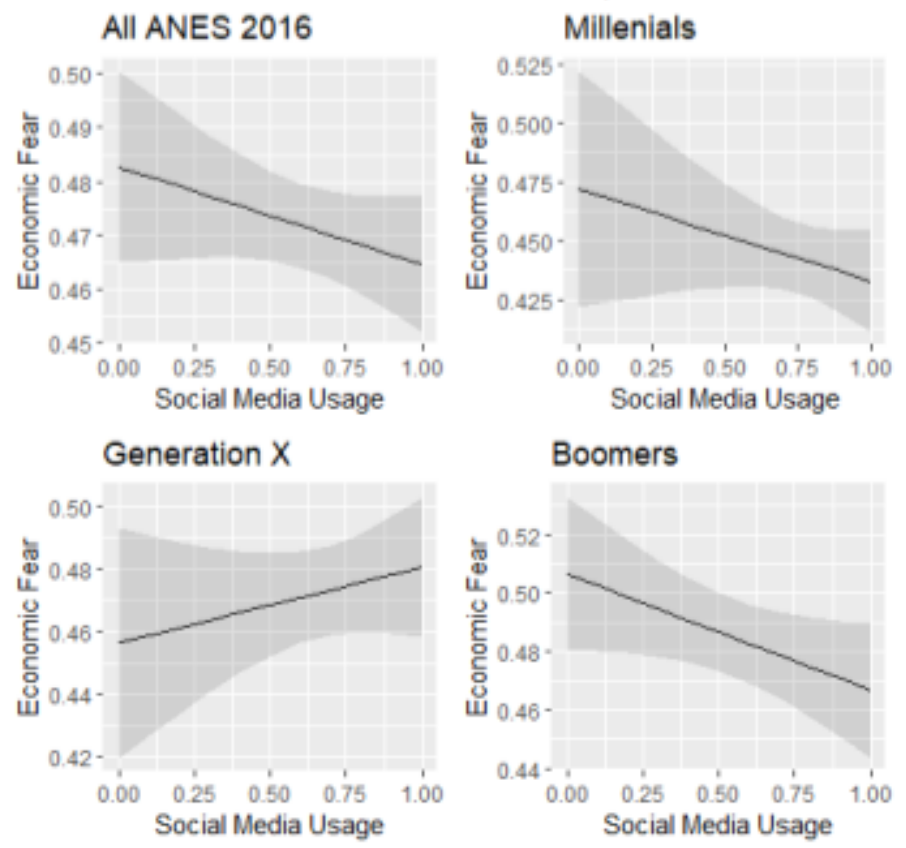

Boomers

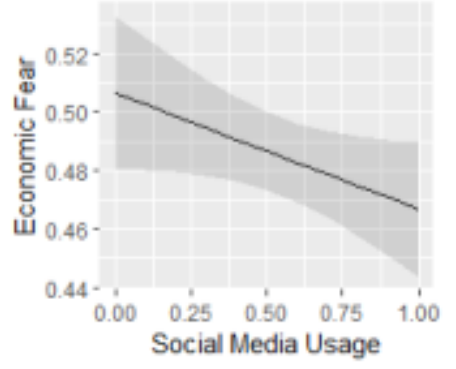

usage may affect voting behavior. Looking at the basic

"Calculus of Voting" equation $\mathrm{R}=\mathrm{pB}-\mathrm{C}+\mathrm{D}$ (Riker \& 
Ordeshook 1968) The person who fears an opposing candidate has an increased likelihood of voting as it affects both the "B" variable, which is the perceived differences between the candidates. If a voter not only disagrees with the candidate, but actively fears them, this suggests that there is like a larger gap between the two options. It may also create an additional effect on the "D" variable, the psychological reward for voting, as it creates a degree of satisfaction about standing up to or opposing something that they fear.

In the 2016 election we saw the highest voter turnout ever after campaigns that led many to fear both candidates. Despite the fact that it was the highest voter turnout, it was not the highest percentage turnout of eligible voters. This effect may have been curtailed by the fact that many people were to some degree afraid of both candidates. Some people may not have seen them as different, but rather that they were choosing between the lesser of two evils. 


\section{CHAPTER 5: DISCUSSION}

My primary purpose is to determine if social media usage influences fear in the United States. The internet is a powerful tool in American culture. It may be able to cause drastic changes in political attitudes, adding to the fear level of the overall population. I hypothesized that social media use will increase exposure to fear-inducing news and political propaganda, therefore increasing fear. Furthermore, this effect is getting stronger and it is strongest among populations that have not grown up expecting sensationalized, partisan news.

It is clear social media usage has an impact on political fear. In 2012 increased social media usage increased the likelihood that a voter would express fear of one of the candidates. In 2016 we were able to see that it affected how often the people felt afraid of the candidate. 
The use of social media did not lead to a more fearful person, as we had expected. Rather, while it increased political fear, it did not increase economic fear, and marginally increased economic optimism. Perhaps people who were using social media were more likely to have support and understand technological development, which is the largest piece of our economic growth.

The theorized increased impact on the older two cohorts was not evident in this data. The theory could be innately wrong, and that they are not as vulnerable to the propaganda and fake news as I originally predicted. It also becomes hard to measure because the study only asks how many days a week that people are using social media. Perhaps, if we were able to control for hours a day used, or which platforms are being used we may see different results.

This effect will likely continue to grow in importance and impact as we as a society get more of our social interaction, media, and news through social media and the internet in general. Its usage has the potential to make us more aware as a society to the plight of others, or to be used by populists and those with ill intentions to further political agendas through fear. 


\section{REFERENCES}

\section{Bibliography}

Alberici, Augusta Isabella, and Patrizia Milesi. "The

Influence of the Internet on the Psychosocial

Predictors of Collective Action." Journal of Community

\& Applied Social Psychology, vol. 23, no. 5, 2012, pp.

373-388., doi:10.1002/casp.2131.

Altheide, David L. "Media Culture and the Politics of Fear" Cultural Studies $\leftrightarrow$ Critical Methodologies 2019, Vol. 19 (1) $3-4$

Altheide, David L. (2004) "Media Logic and Political Communication" Political Communication, 2004, 21:293-296, DOI: 10.1002/SYMB.501

Altheide, David L. (2020) "Pandemic in the Time of Trump: Digital Media Logic and Deadly Politics" Symbolic Interaction, 2020, Vol. 43, Issue 3, pp. 514-540, ISSN: 0195-6086 print/1533-8665 online. 
Altheide, David L. (2009) "The Columbine Shootings and the Discourse of Fear" American Behavioral Scientist Volume 52 Number 10 June 2009 1354-1370

Altheide, David L., \& Michalowski, R. Sam (1999) "Fear in the News: A Discourse of Control" The Sociological Quarterly, Summer, 1999, Vol. 40, No. 3 (Summer, 1999), pp. 475-503

Ashokkumar, Ashwini (2020) "Censoring political opposition online: Who does it and why" Journal of Experimental Social Psychology, Volume 91, November 2020, 104031

Bekmagambetov, Amanzhol, et al. (2018) "Critical social media information flows: political trust and protest behaviour among Kazakhstani college students" CENTRAL ASIAN SURVEY 2018, VOL. 37, NO. 4, 526-545 https://doi.org/10.1080/02634937.2018.1479374

Bertot, John (2003) "The Multiple Dimensions of the Digital Divide: More than the Technology 'Haves' and 'Have Nots" Government Information Quarterly 20 (2003) $185-19$

Bimber, Bruce (1999) "The Internet and Citizen Communication With Government: Does the Medium 
Matter?" Political Communication, 16:4, 409-428, DOI: $10.1080 / 105846099198569$

Blom, Jonas Nygaard, \& Hansen, Kenneth Reinecke (2014)

"Click bait: Forward-reference as lure in online news headlines" Journal of Pragmatics Volume 76, January 2015, Pages 87-100

Boulianne, Shelley, \& Theocharis, Yannis (2020) "Young People, Digital Media, and Engagement: A Meta-Analysis of Research" Social Science Computer Review 2020, Vol. 38 (2) $\quad 111-127$

Chou, Eileen, et al. (2020) "From slacktivism to activism: Improving the commitment power of e-pledges for prosocial causes" PLOS ONE 15(4): e0231314. https://doi.org/10.1371/journal.pone.0231314

DiMaggio, Paul, et al. (2001) "Social Implications Of The Internet" Annu. Rev. Sociol. 2001. 27:307-36

Ekman, Mattias (2015) "Online Islamophobia and the politics of fear: manufacturing the green scare" Ethnic and Racial Studies, 2015 Vol. 38, No. 11, 1986-2002, http://dx.doi.org/10.1080/01419870.2015.1021264 
Enli, Gunn (2017) "Twitter as arena for the authentic outsider: exploring the social media campaigns of Trump and Clinton in the 2016 US presidential election" European Journal of Communication 2017, Vol. $32(1) \quad 50-61$

Fox, Jesse, \& Moreland, Jennifer (2014) "The Dark Side Of Social Networking Sites: An Exploration of The Relational And Psychological Stressors Associated With Facebook Use And Affordances" Computers in Human Behavior, Volume 45, April 2015, Pages 168-176

Friemel, Thomas (2016) "The digital divide has grown old: Determinants of a digital divide among seniors" new media \& society 2016, Vol. 18 (2) 313-331

Gainous, Jason, et al. (2015) "Civic Disobedience: Does Internet Use Stimulate Political Unrest in East Asia?" Journal of Information Technology \& Politics, $12: 219-236,2015$

Gainous, Jason, et al. (2018) "Digital media and political opposition in authoritarian systems: Russia's 2011 and 2016 Duma elections" DEMOCRATIZATION, 2018 VOL. 25, NO. $2, \quad 209-226$ 
Gainous, Jason, et al. (2016) "Internet Freedom and Social Media Effects: Democracy and Citizen Attitudes in Latin America." Online Information Review, vol. 40, no. 5, 2016, pp. 712-738. , doi:10.1108/oir-11-2015-0351.

Gainous, Jason, et al. (2018) "Traditional Versus Internet Media in a Restricted Information Environment: How Trust in the Medium Matters." Political Behavior, vol. 41 , no. 2, 2018, pp. 401-422., doi:10.1007/s11109-018-9456-6.

Gainous, J., \& Wagner, K. M. (2014). Tweeting to power: The social media revolution in American politics. New York: Oxford University Press.

Grover, Purva, et al. (2019) "Polarization and acculturation in US Election 2016 outcomes - Can twitter analytics predict changes in voting preferences" Technological Forecasting \& Social Change Volume 145, August 2019, Pages 438-460

Guillen, Mauro F. \& Suarez, Sandra L. (2005) "Explaining the Global Digital Divide: Economic, Political and Sociological Drivers of Cross-National Internet Use" Social Forces, Volume 84, Number 2, December 2005 
Gunitsky, Seva (2015) "Corrupting the Cyber-Commons: Social Media as a Tool of Autocratic Stability" Perspectives on Politics, $13(1), 42-54$. doi:10.1017/S1537592714003120

Hasell1, A., \& Weeks, Brian E. (2016) "Partisan Provocation: The Role of Partisan News Use and Emotional Responses in Political Information Sharing in Social Media" Human Communication Research, 42 (2016) 641-661 (c) 2016 International Communication Association

Hassid, Jonathan (2012) "Safety Valve or Pressure Cooker? Blogs in Chinese Political Life" Journal of Communication 62 (2012) 212-230

Hindman, Douglas (2000) "The Rural-urban Digital Divide" J\&MC Quarterly Vol. 77, No. 3 Autumn 2000 549-560

Huddy, Leonie, et al. (2005) "Threat, Anxiety, and Support of Antiterrorism Policies." American Journal of Political Science, vol. 49, no. 3, 2005, p. 593., doi:10.2307/3647734.

Hunsaker, Amanda \& Hargittai, Eszter (2018) "A review of Internet use among older adults" new media \& society 2018, Vol. $20(10)$ 3937-3954 
Hsieh, J. J. Po-An, Rai, Arun, \& Keli, Mark (2008)

"Understanding Digital Inequality: Comparing Continued

Use Behavioral Models of The Socio-economically

Advantaged And Disadvantaged" MIS Quarterly Vol. 32

No. 1, pp. 97-126/March 2008

Iyengar, Shanto, and Sean J. Westwood (2014) "Fear and

Loathing across Party Lines: New Evidence on Group

Polarization." American Journal of Political Science,

vol. 59, no. 3, 2014, pp. 690-707.,

doi:10.1111/ajps.12152.

Jost, John T, et al. (2003) "Political Conservatism as

Motivated Social Cognition." Psychological Bulletin,

U.S. National Library of Medicine, May 2003, www.ncbi.nlm.nih.gov/pubmed/12784934/.

Kalsnes, Bente, \& Larsson, Anders (2018) "UNDERSTANDING

NEWS SHARING ACROSS SOCIAL MEDIA Detailing

distribution on Facebook and Twitter" Journalism

Studies, 2018 Vol. 19, No. 11, 1669-1688,

https://doi.org/10.1080/1461670x.2017.1297686

Katzenbach, C. \& Ulbricht, L. (2019) "Algorithmic

governance" Internet Policy Review, 8(4). DOI:

$10.14763 / 2019.4 .1424$ 
Knoll, Johannes, et al. (2020) "The social media political participation model: A goal systems theory perspective" Convergence: The International Journal of Research into New Media Technologies 2020, Vol. 26(1) $135-156$

Kramer, Adam, et al. (2014) "Experimental evidence of massive-scale emotional contagion through social networks" Proceedings of the National Academy of Sciences of the United States of America, June 17, 2014, Vol. 111, No. 24 (June 17, 2014), pp. 8788-8790

Kristofferson, Kirk, et al. (2014) "The Nature of Slacktivism: How the Social Observability of an Initial Act of Token Support Affects Subsequent Prosocial Action" Journal of Consumer Research, Inc. Vol. 40 April 2014

Kruglanski, Arie, et al. (2015) "The Rocky Road From Attitudes to Behaviors: Charting the Goal Systemic Course of Actions" Psychological Review, 2015, Vol. 122, No. 4, $598-620$

Lewis, Seth C., \& Molyneaux, Logan (2018) "A Decade of Research on Social Media and Journalism: Assumptions, Blind Spots, and a Way Forward" Media and 
Communication (ISSN: 2183-2439)2018, Volume 6, Issue 4, Pages 11-23 DOI: 10.17645/mac.v6i4.1562

Lucas, G. (1999). "Star wars, episode I, the phantom menace: Illustrated screenplay" New York: Ballantine.

Mackuen, Michael, et al. (2010) "Civic Engagements:

Resolute Partisanship or Reflective Deliberation." American Journal of Political Science, vol. 54, no. 2, 2010, pp. 440-458.,

doi:10.1111/j.1540-5907.2010.00440.x.

Niehaves, Björn \& Plattfaut, Ralf (2014) "Internet adoption by the elderly: employing Is technology acceptance theories for understanding the age-related digital divide" European Journal of Information Systems (2014) 23, 708-726

Oxley, D. R., et al. (2008) "Political Attitudes Vary with Physiological Traits." Science, vol. 321, no. 5896, 2008, pp. 1667-1670., doi:10.1126/science.1157627.

Peters, Chris (2011) "Emotion aside or emotional side? Crafting an 'experience of involvement' in the news" Journalism $12(3) \quad 297-316$ 
Putnam, RD (2000) "Bowling Alone: The Collapse and Revival of American Community" New York: Simon \& Schuster; 2000 .

Przybylski, Andrew K., et al. (2013) "Motivational, emotional, and behavioral correlates of fear of missing out" Computers in Human Behavior, Volume 29, Issue 4, July 2013, Pages 1841-1848

Riker, William H., and Peter C. Ordeshook (1968) "A Theory of the Calculus of Voting." American Political Science Review, vol. 62, no. 1, 1968, pp. 25-42., doi:10.2307/1953324.

Rosen, L.D., et al. (2013) "Is Facebook creating "iDisorders"? The link between clinical symptoms of psychiatric disorders and technology use, attitudes and anxiety" Computers in Human Behavior, Volume 29, Issue 3, May 2013, Pages 1243-1254

Rothmen, Lily (2016) "Why Americans Are More Afraid Than They Used to Be" Time, January 6, 2016, https://time.com/4158007/american-fear-history/

Scheller, Simon (2019) "The Strategic Use of Fear Appeals in Political Communication" Political Communication, $36: 586-608,2019$ 
Stieglitz, Stefan \& Dang-Xuan, Linh (2013) "Emotions and Information Diffusion in Social Media-Sentiment of Microblogs and Sharing Behavior" Journal of Management Information Systems, Spring 2013, Vol. 29, No. 4, pp. 217-247.

Strauss, Neil (2016) "Why We're Living in the Age of Fear" Rolling Stone, October 6, 2016, https://www.rollingstone.com/politics/politics-feature s/why-were-living-in-the-age-of-fear-190818/

Valentino, Nicholas A. et al. (2011) "Election Night's Alright for Fighting: The Role of Emotions in Political Participation" The Journal of Politics, Vol. 73, No. 1, January 2011, Pp. 156-170

Widmann, Tobias (2020) "How Emotional Are Populists Really? Factors Explaining Emotional Appeals in the Communication of Political Parties" Political Psychology, Vol. 0, No. 0, 2020 doi: $10.1111 /$ pops. 12693

Wollebæk, Dag, et al. (2019) "Anger, Fear, and Echo Chambers: The Emotional Basis for Online Behavior." Social Media + Society, vol. 5, no. 2, 2019, p. 205630511982985 ., doi:10.1177/2056305119829859. 


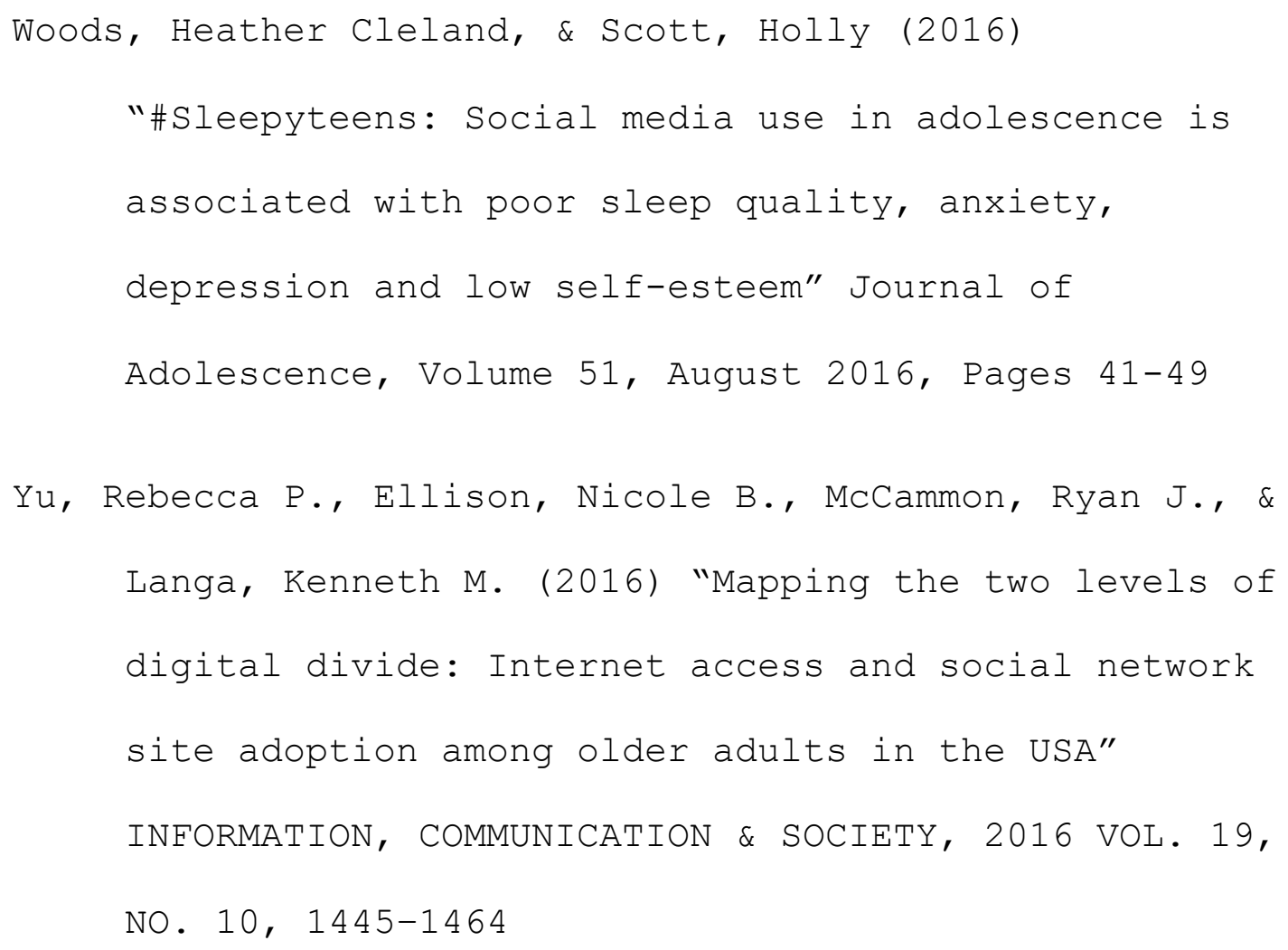




\section{CURRICULUM VITA}

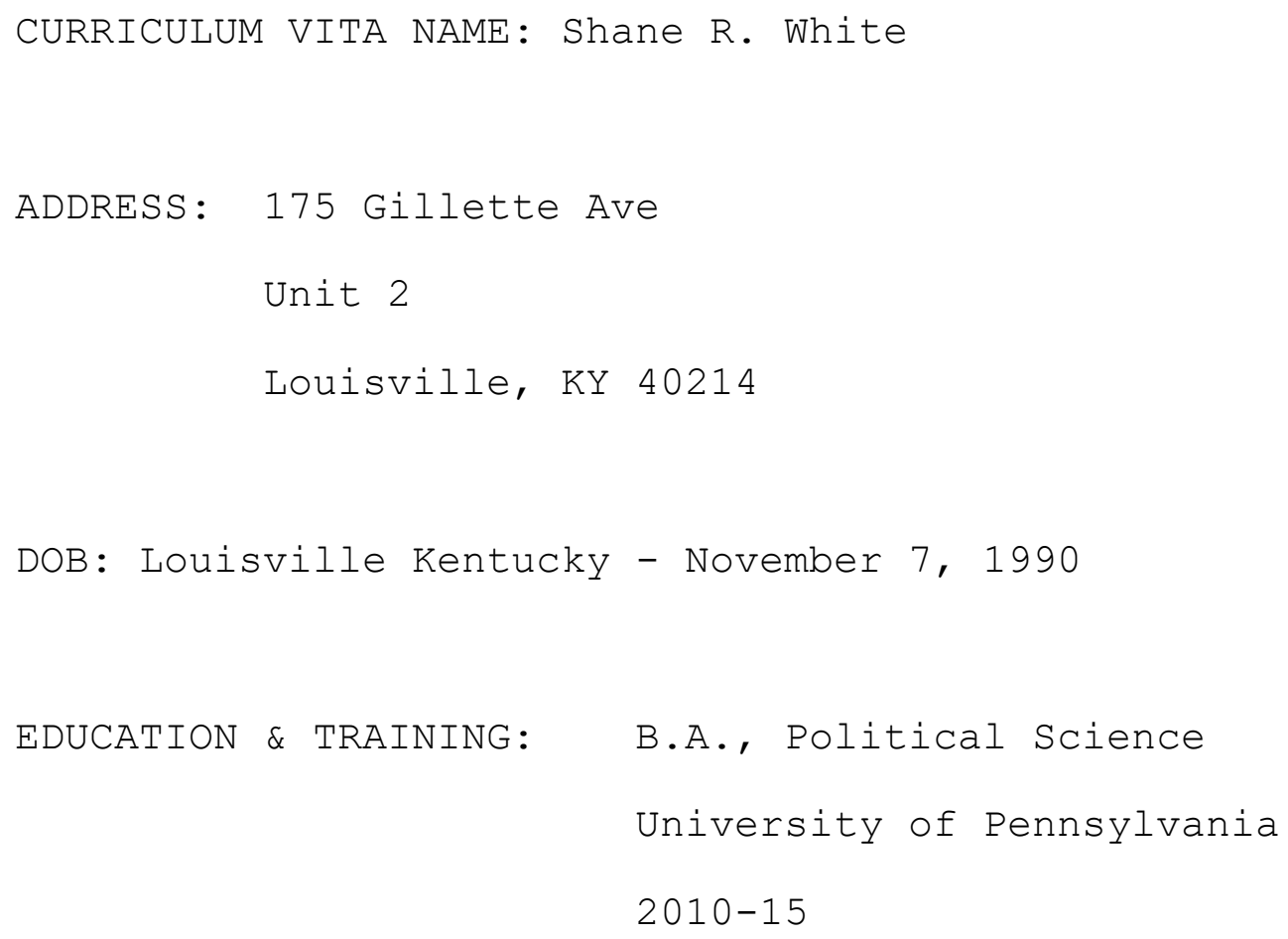

